\title{
Enforcing the Sustainable Groundwater Management Act
}

\author{
An interview with Sam Boland-Brien, Groundwater Management Program Chief, California State \\ Water Resources Control Board
}

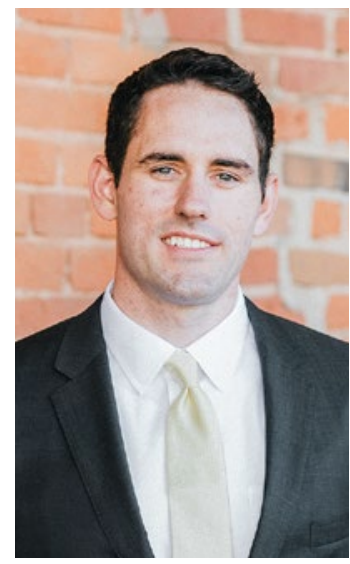

Sam Boland-Brien

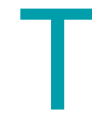

he State Water Resources Control Board (SWRCB) and the California Department of Water Resources (DWR) are the two state agencies overseeing the Sustainable Groundwater Management Act (SGMA). They have distinct roles. In general, DWR acts as a facilitator and evaluator - for instance, assisting with groundwater data management, helping local groundwater sustainability agencies (GSAs) to develop and follow plans that will lead to sustainable management, and evaluating plans once they are developed. SWRCB, by contrast, has more of an enforcement role. It is the agency authorized and empowered to ensure that basins comply with the law's requirements. Sam Boland-Brien leads these efforts as chief of the SWRCB Groundwater Management Program.

\section{To start with, tell us about SWRCB's role in implementing SGMA, and what work you're doing leading up to the first deadline for groundwater sustainability plan submission in January 2020.}

The legislation gives us the broad layout of what we're supposed to do, and our task has been to turn those general authorities into specific actions. We've been preparing the tools and processes that need to be in place so that we can act when needed. Day-to-day, we're answering the many specific questions that come up about SGMA. We're working with DWR, to make sure that we are in sync, for instance with managing groundwater data, and in developing systems for pumpers and GSAs to conveniently submit data. We're also exploring satellite-based monitoring approaches where possible, so we don't have to have as many staff in the field. And we're focusing on developing scalable processes, so that, if it turns out that we suddenly need to manage multiple basins in the future, we'll be able to adapt and expand quickly.

In a lot of areas, county involvement has been really helpful. That's one of the nice elements of SGMA that it's bringing more counties into the groundwater management process. There was already the recognition that land use planning is an important aspect of water resource planning, and now SGMA calls out explicitly that the county can be a first backstop, before state regulators get involved. Counties, for instance, are managing areas that weren't covered by a GSA. I think there are many interesting future opportunities for creative local solutions that involve actions by counties
- actions that could possibly demonstrate to the state that intervention isn't necessary.

\section{Give us some more detail about how SWRCB's enforcement role is likely to play out.}

First, it's important to remember that enforcement starts at the local level, with the GSAs. One of the big things that SGMA does is to give a lot of authority to GSAs. They can levy fees, they can order a pumper to stop pumping, and infractions are linked to civil penalties. The legislation gave them a bunch of tools though we still have to see how the GSAs will settle into using them.

It's only when DWR finds that a groundwater sustainability plan (GSP) - or its implementation - is inadequate, and sees that the issues aren't getting fixed, that the Board becomes involved. With each plan, DWR will be evaluating whether it is it likely to achieve sustainability: does it lay out projects and actions that are going to bring the basin into balance in 20 years. Each plan also needs to set milestones every 5 years, and DWR will be evaluating whether those are adequate, and whether the GSAs are doing what they said they were going to do.

Basins run the risk of state intervention if they miss the deadline for plans or don't have a plan that DWR thinks will be sustainable. Say a GSA fails to adopt a GSP in time. The GSA would go before the Board (the five board members of the SWRCB), and the Board would issue a decision on whether or not to proceed with enforcement action. The Board could designate the basin probationary and lay out the deficiencies, with the consequence being that if those deficiencies are not remedied, the Board will proceed with its own plan until the issues are fixed. While a basin was probationary, all of the pumpers in the basin would be required to submit their groundwater pumping data directly to the SWRCB. The SWRCB would use the data to develop an interim plan and would provide the data publically as a resource for stakeholders in the basin.

That kind of interim plan wouldn't have much flexibility: we'd require monitoring, collect pumping data, and set a schedule for certain corrective actions - likely reduced pumping. SGMA gives us that blunt instrument - reducing pumping - and we would probably use it.

I have been told that no one wants to be first through the Board's enforcement process. Folks 
understand that the first time through, we are probably going to need to be firm so that it is clear the Board is serious about the prospect of state intervention.

\section{What are some of the pros and cons of SGMA's prescriptions being somewhat flexible, with sus- tainability defined as the avoidance of six types of impacts (see page 4) to a "significant and un- reasonable" degree?}

I appreciate that SGMA is outcome-based. It establishes a framework for local agencies to set targets and then the state holds them to those targets. It would be hard for us at the state level to be that flexible. The local-level implementation gives local agencies some flexibility about how to get to the finish line, and also about what the finish line is. Under SGMA, the GSAs define what "significant and unreasonable" impacts look like. Those impacts do have to be quantified - the law says that there need to be clear "minimum thresholds" and "measurable objectives" - and they are subject to review by DWR, as a reasonableness check. But there's still a lot of flexibility, and SWRCB is kept at a distance from those processes.

As for the cons: At the end of the day, there's still going to be, in many cases, the core issue of determining how much individuals can pump. At the state level, SGMA doesn't want us to presume that pumping restrictions are necessarily going to be required in any given basin. But we wouldn't want a GSA to get so wrapped up in trying to figure out what is "sustainable" that it delays dealing with the fact that you still need to divide the pie.

\section{Closing thoughts?}

With your audience being significantly in agriculture, I think another important part of SGMA is the need for having a broad buy-in and consensus as GSAs move through the GSP process. There's going to have to be really serious engagement with the various groundwater users in each basin, including growers and dairy operators. Folks need to be part of the decision-making process, and to buy in to the implementation process. That's why we've been working a lot on outreach and think GSAs need to emphasize outreach if they want to move to implementation successfully. We've been trying to work with the county Farm Bureau offices, and we'd like to do more with UC Cooperative Extension to help those in agriculture understand SGMA. CA

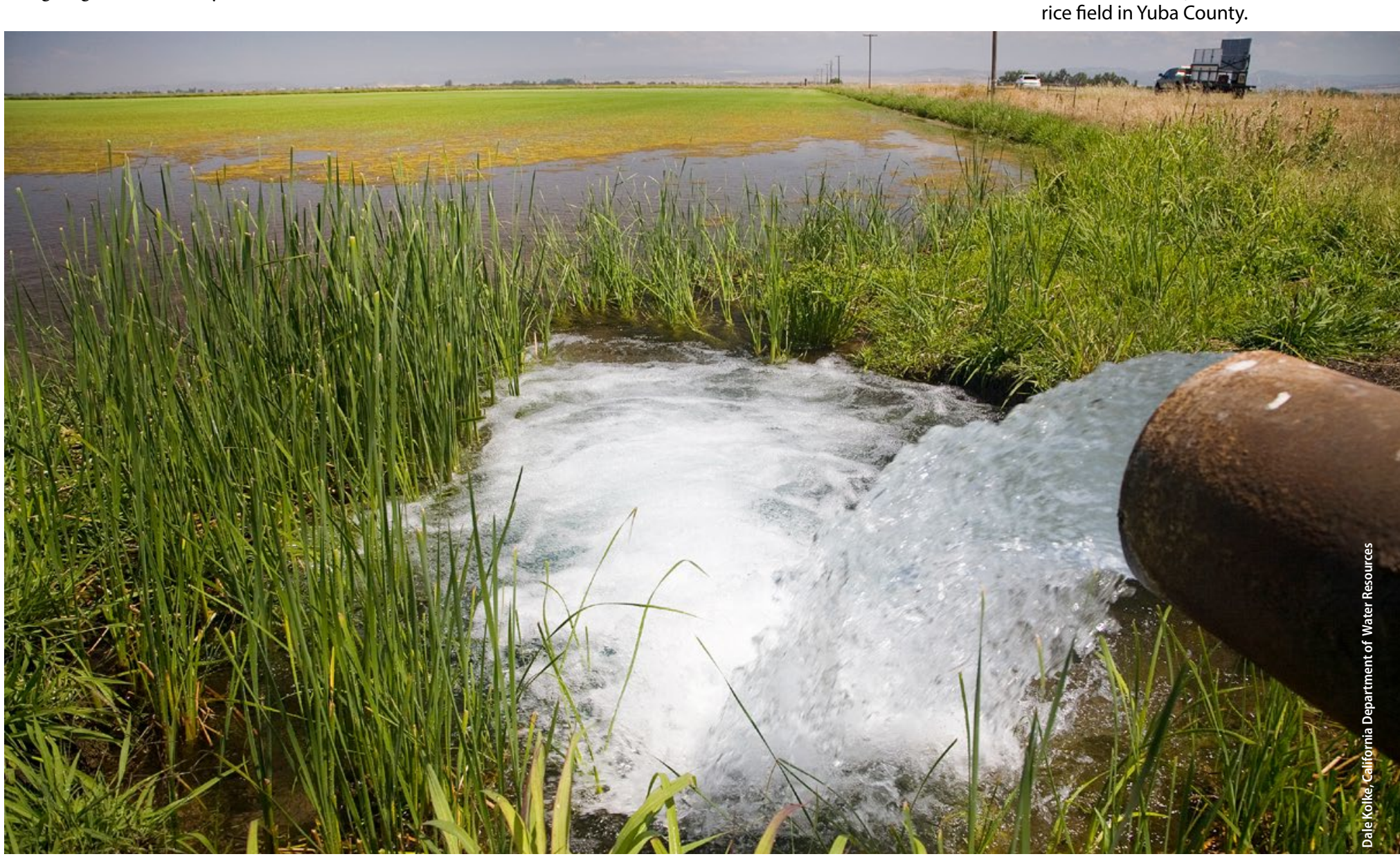

